\title{
Comfort IAQ - a new tool to simulate the indoor particulate matter pollution in relation to the chosen supply air filter quality
} Tobias Zimmer ${ }^{1 *}$

\author{
${ }^{1}$ Camfil AB, Product Management, Germany
}

\begin{abstract}
Many factors are rather well known for their ability to create a good indoor air climate, but when it comes to airborne particles, there is no great deal of documentation to consult and set requirements. Nor are there much of other specific guidelines. The new, product-neutral and free online calculation tool Comfort IAQ helps to understand the mechanisms behind IAQ and gives a good indication on what would be the impact on indoor air quality (IAQ) due to air exchange, outdoor air environment, air filter selection and building envelope characteristics. Comfort $I A Q$ allows to simulate the concentrations of Particulate Matter (PM1, PM2.5, PM10) in a specific ventilated room, depending on the chosen supply air filter quality. To model the room and the supply air conditions in a realistic way, Comfort IAQ allows to define besides outdoor air conditions (ODA) also the room dimensions, the air changes, the recirculation air rate as well as the supply air filter quality (based on ISO 16890, EN779 or ASHRAE 52.2). Based on these values, the Comfort IAQ tool provides an estimation of the indoor particle concentration and gives engineers and planers a good tool to optimize the Indoor Air Quality, by choosing the best combinations of supply air filter qualities and ventilation rates for a specific application. The algorithms in the online tool Comfort IAQ have been developed by Lars Ekberg, (Docent-installallationsteknik, Chalmers Tekniska Högskola) and the accuracy of the calculations was verified by comparing them with measurements in a full-scale test chamber.
\end{abstract}

\section{Introduction}

\subsection{Background}

Many factors are rather well known for their ability to create a good indoor climate, but when it comes to airborne particles, there is not a great deal of documentation from an environmental medicine standpoint for government agencies to consult and set requirements. Nor are there any other specific guidelines. In 2006, the National Board of Health and Welfare (Socialstyrelsen) in Sweden concluded in a report that it was important to minimize particle concentrations in both indoor and outdoor air from a health perspective. Today this means, in most cases, that Class F7 filters are installed as the de facto standard in Sweden, even if it is not actually known if filters of this efficiency are sufficient. A similar situation can be found in Germany, where the German Standard VDI 6022 required F7 filters acc. EN779 as a minimum requirement for supply in non-residential buildings for many years, before this minimum requirement was modified in 2017 to ePM1 50\% acc. ISO 16890, related to the fact that ISO 16890 superseded the EN779:2012 in 2018 .

The newly developed online application Comfort IAQ allows to simulate the effects of air filters on the indoor air quality. The calculations used in Comfort IAQ are based on a study from Lars Ekberg (2016). This study contains calculations of airborne particle concentrations in indoor air that have their source in outdoor air. The investigation was focused on studying how different choices of supply air filters are expected to impact the presence of particles indoors. The investigation covers residential buildings, offices and classrooms. The accuracy of the calculations was verified by comparing them with measurements in a full-scale test chamber.

\subsection{Purpose of Comfort IAQ}

The purpose of the new, product-neutral and free online calculation tool Comfort IAQ is, to help to understand the mechanisms behind IAQ and to give a good indication on what would be the impact on indoor air quality (IAQ) due to air exchange, outdoor air environment, air filter selection and building envelope characteristics.

Comfort IAQ allows to simulate the concentrations of Particulate Matter (PM1, PM2.5, PM10) in a specific ventilated room, depending on the chosen supply air filter quality. To model the room and the supply air conditions in a realistic way, Comfort IAQ allows to define besides outdoor air conditions (ODA) also the room dimensions, the air changes, the recirculation air rate as well as the supply air filter quality (based on ISO 16890, EN779 or ASHRAE 52.2)

Based on these values, the Comfort IAQ tool provides an estimation of the indoor particle concentration and gives engineers and planers a good tool to optimize the Indoor Air Quality, by choosing the best combinations of supply

\footnotetext{
* Corresponding author: tobias.zimmer@camfil.com
} 
air filter qualities and ventilation rates for a specific application.

\section{Comfort IAQ}

The product neutral and free online calculation tool Comfort IAQ allows to model a specific ventilated room and simulate the indoor particle concentration based on the selected ventilation rates, filter classes and outdoor air conditions.

\subsection{Calculation model}

The Calculation model used in Comfort IAQ was developed by Lars Ekberg (2016). Figure 1 shows a sketch of the building model used. Indoor sources of particles have not been considered in the model.

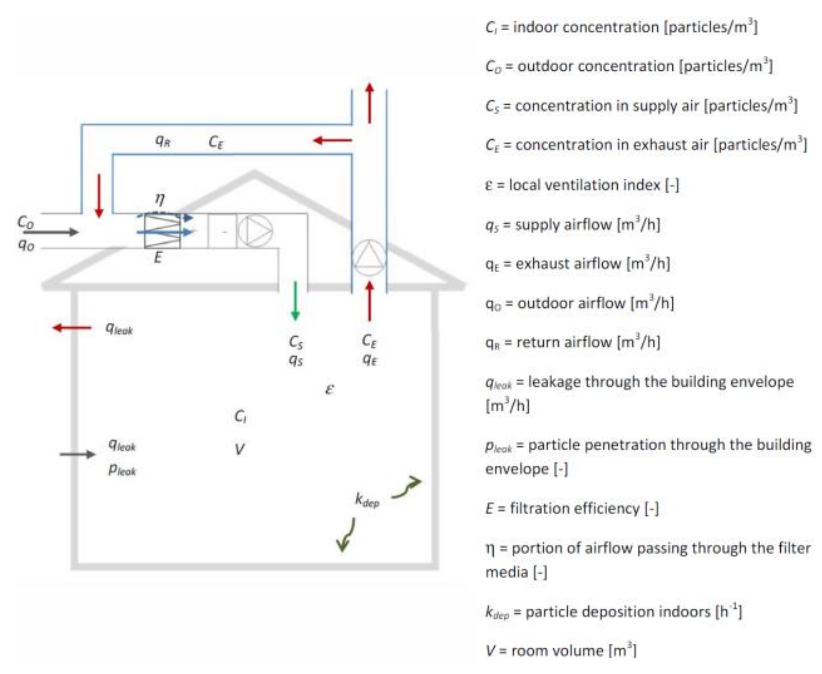

Figure 1. Sketch of a ventilated building with a mechanical supply air and exhaust air ventilation system in which part of the exhaust air can be recirculated and mixed with the outdoor airflow before passing through the air filter. (L. Ekberg, 2016)

"If the conditions do not vary over time, and the particle concentration in the indoor air is constant, the concentration is said to be at steady state. In this case, the number of particles introduced through the ventilation system is as large as the number removed. A balance equation can be prepared. After "simplification", the following equation (1) is derived:" (L. Ekberg, 2016)

$$
C_{I}=C_{U} \frac{(1-\eta \cdot E) \varepsilon \cdot q_{O}+p_{\text {leak }} \cdot q_{\text {leak }}}{\varepsilon\left(q_{O}+q_{R}\right)+q_{\text {leak }}+k_{\text {dep }} \cdot V-(1-\eta \cdot E) \varepsilon \cdot q_{R}}
$$

This Equation above is used as the basis for Comfort $I A Q$ to predict the effects of a specific one stage filtration in a specific modelled building (details see 2.2).

\subsection{Defining the application in Comfort IAQ}

Based on the calculation model described in 2.1, the Comfort IAQ allows to simulate the concentrations of Particulate Matter (PM1, PM2.5, PM10) in a specific ventilated room, depending on the chosen supply air filter quality. To do this, you define in a first step the specific room parameters, like room dimensions, number of air changes, percentage of return air, as well as the outdoor conditions (see figure 2).

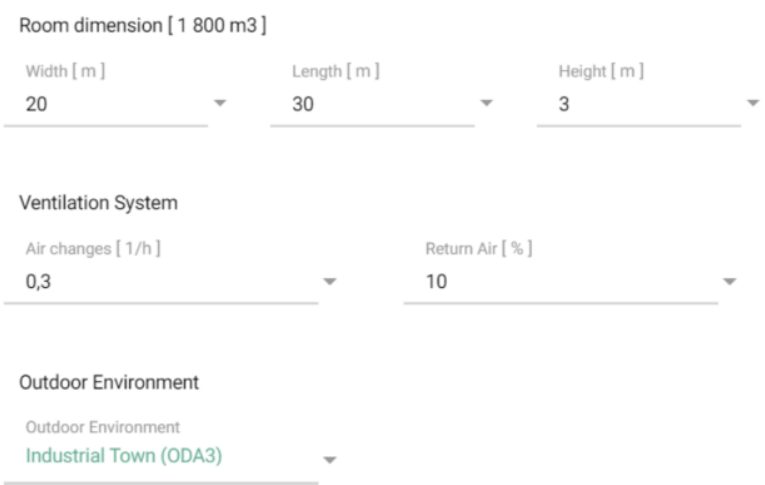

Figure 2. Menu to define the room parameters in Comfort IAQ

For all fields from the menu to define the room parameters (see figure 2), you can choose from predefined drop-down menus. For defining the outdoor air conditions, the values for the different outdoor environments in the drop-down menus are based on definitions given in EN 16798-3 (annual mean values for $\mathrm{PMx}$ ) as well as on typical measurement results (annual mean values for PMx) obtained from outdoor air measurements in different environments (see figure 3 ).

\section{Outdoor Environment \\ Rural area (ODA1) [ PM1 $=6 \mu \mathrm{g} / \mathrm{m}^{3} ; \mathrm{PM} 2,5=9 \mu \mathrm{g} / \mathrm{m}^{3}$ ] \\ Country town [PM1 $=8 \mu \mathrm{g} / \mathrm{m}^{3} ; \mathrm{PM} 2,5=12 \mu \mathrm{g} / \mathrm{m}^{3}$ ] \\ Large Town (ODA2) [PM1 $=16 \mu \mathrm{g} / \mathrm{m}^{3} ; \mathrm{PM} 2,5=24 \mu \mathrm{g} / \mathrm{m}^{3}$ ] \\ Industrial Town (ODA3) [PM1 $=23 \mu \mathrm{g} / \mathrm{m}^{3} ; \mathrm{PM} 2,5=36 \mu \mathrm{g} / \mathrm{m}^{3}$ ] \\ Industrial area [ PM1 =39 $\mu \mathrm{g} / \mathrm{m}^{3} ; \mathrm{PM} 2,5=60 \mu \mathrm{g} / \mathrm{m}^{3}$ ] \\ CANCEL OK}

Figure 3. Menu for the outdoor environment in Comfort IAQ

An overview of the selected room settings is given by Comfort IAQ for documentation purposes (see figure 4). 


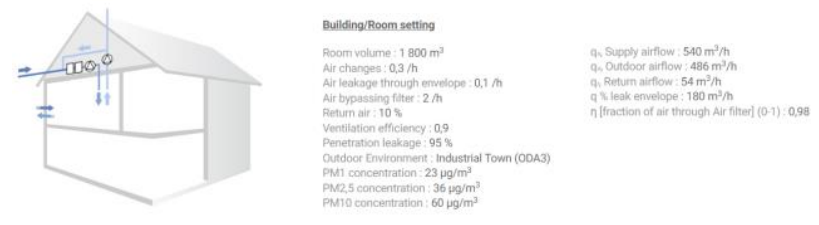

Figure 4. Summary of the selected settings in Comfort IAQ

\subsection{Selecting air filters in Comfort IAQ}

You can choose in Comfort IAQ from a selection of generic air filters. Those air filters are classified according the three most relevant rating standards for supply air filters for general ventilation: ISO 16890, EN 779:2012, ASHRAE 52.2. (see figure 5).

The predefined efficiencies of these filters against particulate matter PM1, PM2,5 as well as against PM10 are based on the measured efficiencies of typical filters of those filter classes in a test rig acc. ISO 16890.

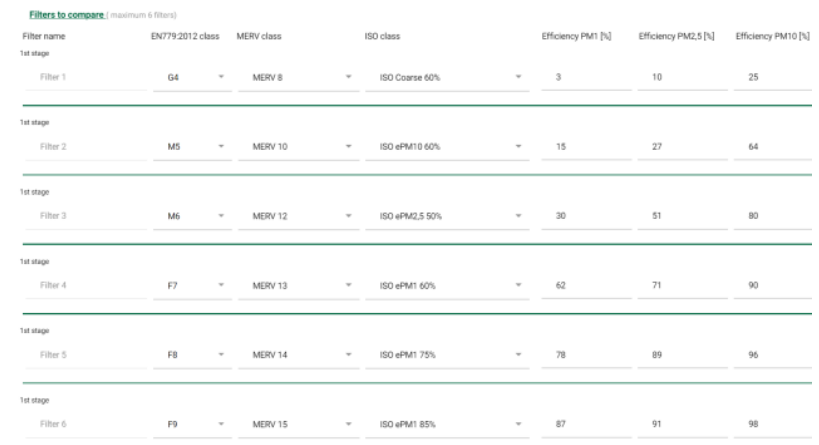

Figure 5. Selectable air filters in Comfort IAQ

The Comfort IAQ application allows exclusively the selection of a one-stage filtration of the supply air. In these conditions, up to 6 different air filter classes can be compared directly, based on the chosen definition of your specific application (see 2.2).

\subsection{Presentation of results in Comfort IAQ}

The presentation of the effects of the different air filters on the concentration of PM1, PM2,5 and PM10 indoors in the selected application conditions can be extracted as a summary table (figure 6).

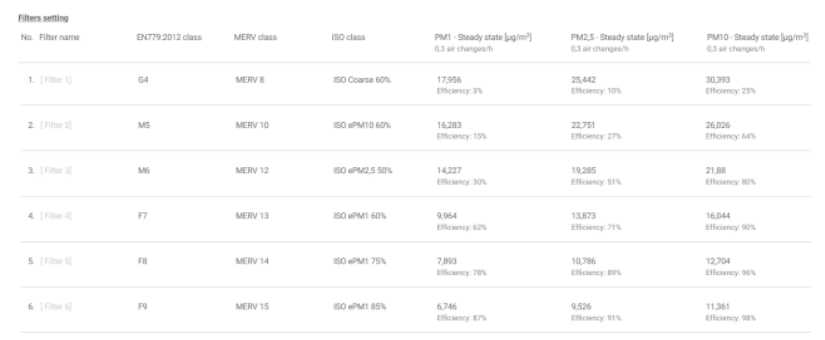

Figure 6. Summary table of PM efficiencies in Comfort IAQ
To visualise the reduction of PM1, PM2,5 and PM10 in the given setting, those data can also be obtained as separate graphs for PM1 (figure 7), PM2,5 (figure 8), PM10 (figure 9).

This split into three separate graphs can be most helpful, as the reduction of these different fractions of particulate matter may require different filtration solutions. For instance, the reduction of the PM1 concentration indoors could be most important, as this fraction of the smallest particles has the biggest effect on human health.

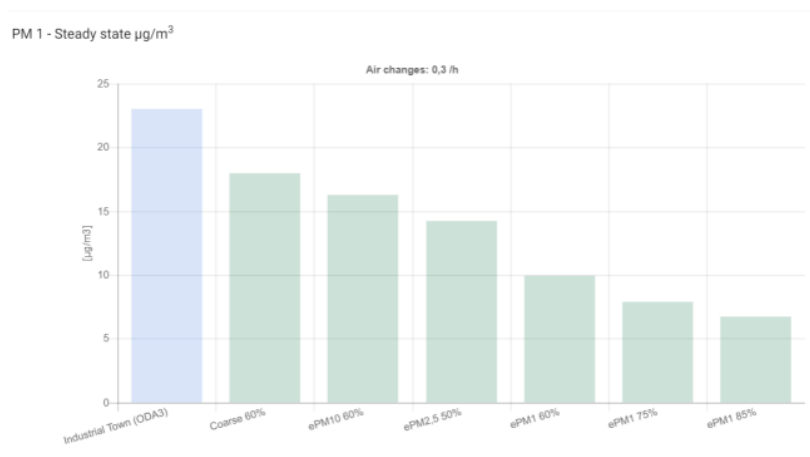

Figure 7. PM1 concentrations outdoors versus indoors in the selected conditions in relation to the selected supply air filters

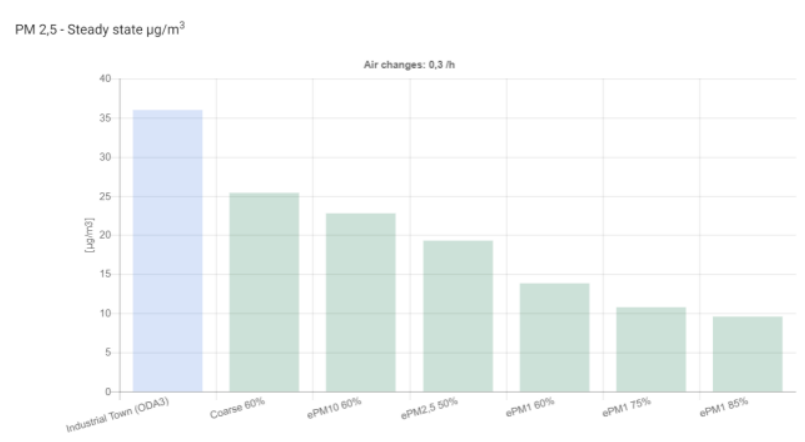

Figure 8. PM2,5 concentrations outdoors versus indoors in the selected conditions in relation to the selected supply air filters

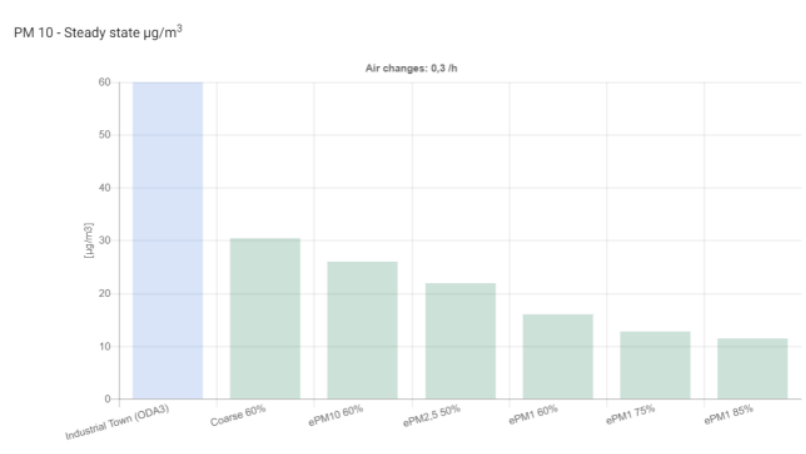

Figure 9. PM10 concentrations outdoors versus indoors in the selected conditions in relation to the selected supply air filters

In addition to the efficiencies against the different fractions of particulate matter (PM), Comfort IAQ also 
provides graphs of the effects of increasing or decreasing the number of air changes on the particulate matter concentrations indoors (see figure 10).

This function is beneficial to optimise the ventilation system in terms of air changes, as increasing the number of air changes only reduces the particulate matter indoors, if sufficiently efficient air filters are chosen. So choosing a sufficient air filter efficiency is necessary, to benefit from an increased number of air changes.

On the contrary, increasing the number of air changes in combination with an air filter of very low efficiency may even increase the indoor pollution with particulate matter and therefore may decrease the indoor air quality.

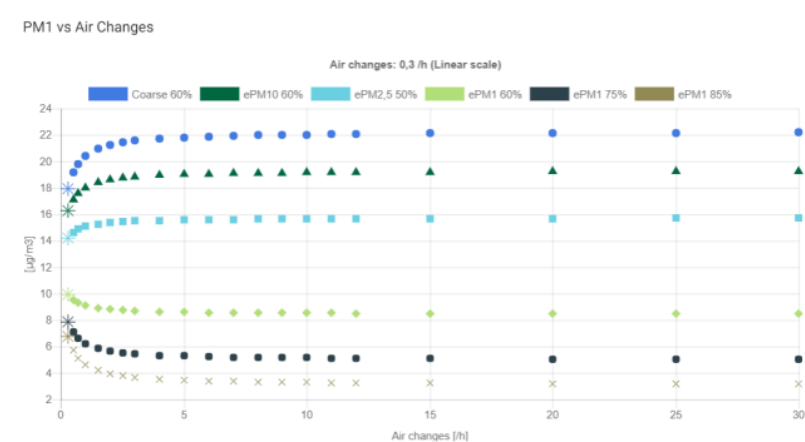

Figure 10. PM1 concentrations indoors in relation to the number of air changes and the selected air filters

In the example graph given in figure 10, only air filters with a filter class of ePM1 $60 \%$ or higher according ISO 16890 would significantly reduce the PM1 concentration indoors and the effect on the PM1 concentration indoors would be positively influenced by an increased number of air changes. In case of the use of filters with significantly lower efficiencies, an increased number of air changes would even increase the indoor particle concentration of PM1.

Reports with all results can be downloaded as PDF documents and can be used free of charge for planning and documentation purposes (see figure 11).
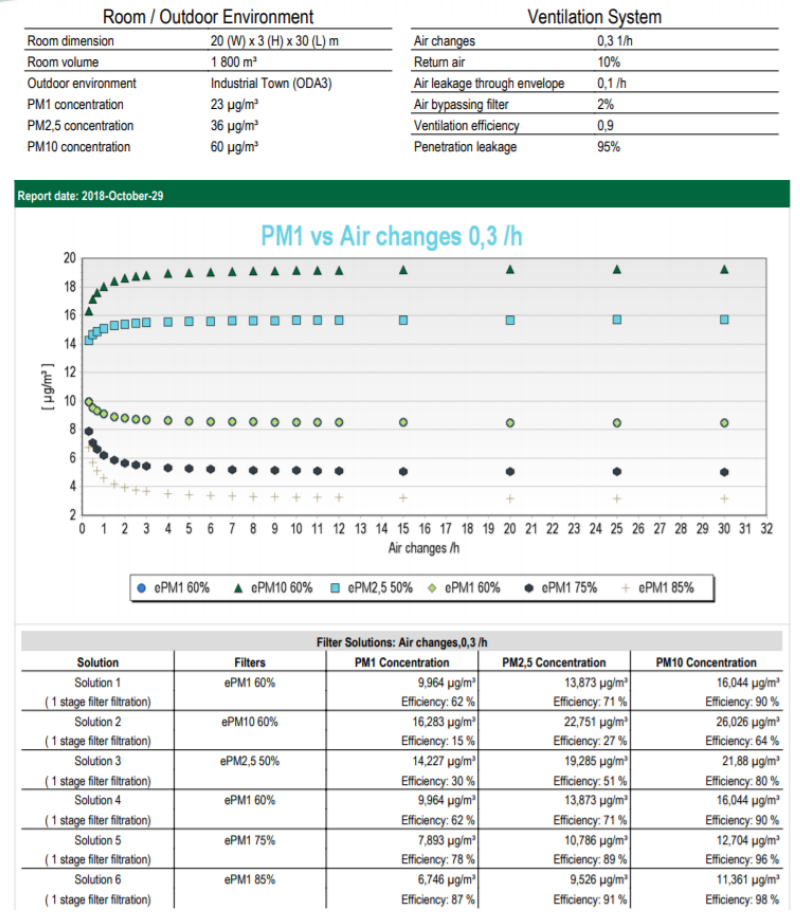

Figure 11. Comfort $I A Q$ Report

\section{Conclusions}

The new, product-neutral and free online calculation tool Comfort IAQ helps to understand the mechanisms behind IAQ and gives a good indication on what would be the impact on indoor air quality (IAQ) due to air exchange, outdoor air environment, air filter selection and building envelope characteristics.

The calculation formulas used in Comfort IAQ is based on a building model developed by Lars Ekberg in 2016. The accuracy of the calculations was verified by comparing them with measurements in a full-scale test chamber. It must be noted, that the model does not take any internal sources of pollution into consideration. Also, the model only takes one filter stage in the supply air into consideration.

Taking these limitations into consideration, Comfort IAQ still offers a unique and easy to use way to predict the impact of supply air filters on the indoor air quality in a given room.

\section{References}

1. L. Ekberg, Importance of ventilation filters for particle concentrations in indoor air (2016)

2. ASHRAE Standard 52.2-2017 - Method of Testing General Ventilation Air-Cleaning Devices for Removal Efficiency by Particle Size (ANSI Approved) - ASHRAE (2017)

3. EN 779:2012, Particulate air filters for general ventilation - Determination of the filtration 
performance, CEN - European Committee for Standardization (2012)

4. EN 16798-3 CEN, Energy performance of buildings - Ventilation for buildings - Part 3: For nonresidential buildings - Performance requirements for ventilation and room-conditioning systems European Committee for Standardization (2012)

5. EN ISO 16890-1, Air filters for general ventilation - Part 1: Technical specifications, requirements and classification system based upon particulate matter efficiency (ePM), CEN - European Committee for Standardization (2016)

6. EN ISO 16890-2, Air filters for general ventilation - Part 2: Measurement of fractional efficiency and air flow resistance, CEN - European Committee for Standardization (2016)

7. Socialstyrelsen, Swedish National Board of Health and Welfare (2006), Partiklar i inomhusmiljön en litteraturgenomgång.

http://www.folkhalsomyndigheten.se/publiceratmate rial/publikationer/Partiklar-i-inomhusmiljon---enlitteraturgenomgang/

8. VDI 6022, Part 1, 01 :2018, Ventilation and indoorair quality, Hygiene requirements for ventilation and air-conditioning systems and units (VDI Ventilation Code of Practice), VDI - Verein Deutscher Ingenieure (2018) 